\title{
Preventing the collapse of 3D bacterial cellulose network via citric acid
}

\author{
A. Meftahi ${ }^{1} \cdot$ R. Khajavi ${ }^{2}$ - A. Rashidi ${ }^{1} \cdot$ M. K. Rahimi ${ }^{3} \cdot$ A. Bahador $^{4}$ \\ Received: 27 March 2018 / Accepted: 6 August 2018 / Published online: 17 August 2018 \\ (c) The Author(s) 2018
}

\begin{abstract}
Bacterial cellulose (BC) is a three-dimensional interconnected network of biosynthesized nanofibers. Its rehydration potential would be reduced significantly after its first drying, as a result of entanglement and jamming of cellulose polymer chains. Consequently, its versatility would be also reduced to some limited applications in which repeated water absorbance potential is not of great importance. This study aims to prevent the drawback of carboxylic bridging/cross-linking between cellulose polymer chains. Ten-day-cultured BC pellicles were immersed in various citric acid solutions (as bridging agent) and cured at $160{ }^{\circ} \mathrm{C}$ for $5 \mathrm{~min}$. The formation of bridges was confirmed using attenuated total reflection-fourier transform infrared spectroscopy. Scanning electron microscope images showed that there is a different porosity bridged/cross-linked $\mathrm{BC}$ specimens (XBC). According to Brunauer-Emmett-Teller analysis, the surface area of XBC (20 w/v \% with catalyst) got 87.5 times larger than that of the unbridged/pristine $\mathrm{BC}$ (PBC). X-ray diffraction patterns showed no change of crystallinity of XBC in comparison with PBS. The thickness and wettability of XBC samples were 137 and 3.27 times more than PBC samples orderly. Furthermore, the water swelling rate increased significantly for $\mathrm{XBC}$ in comparison with PBC. Meanwhile, treated samples had lower elongation and strength than normal BC. The conclusion is that XBC could conserve its repeated absorbency potential after the presented process.
\end{abstract}

Extended author information available on the last page of the article 


\section{Graphical abstract}

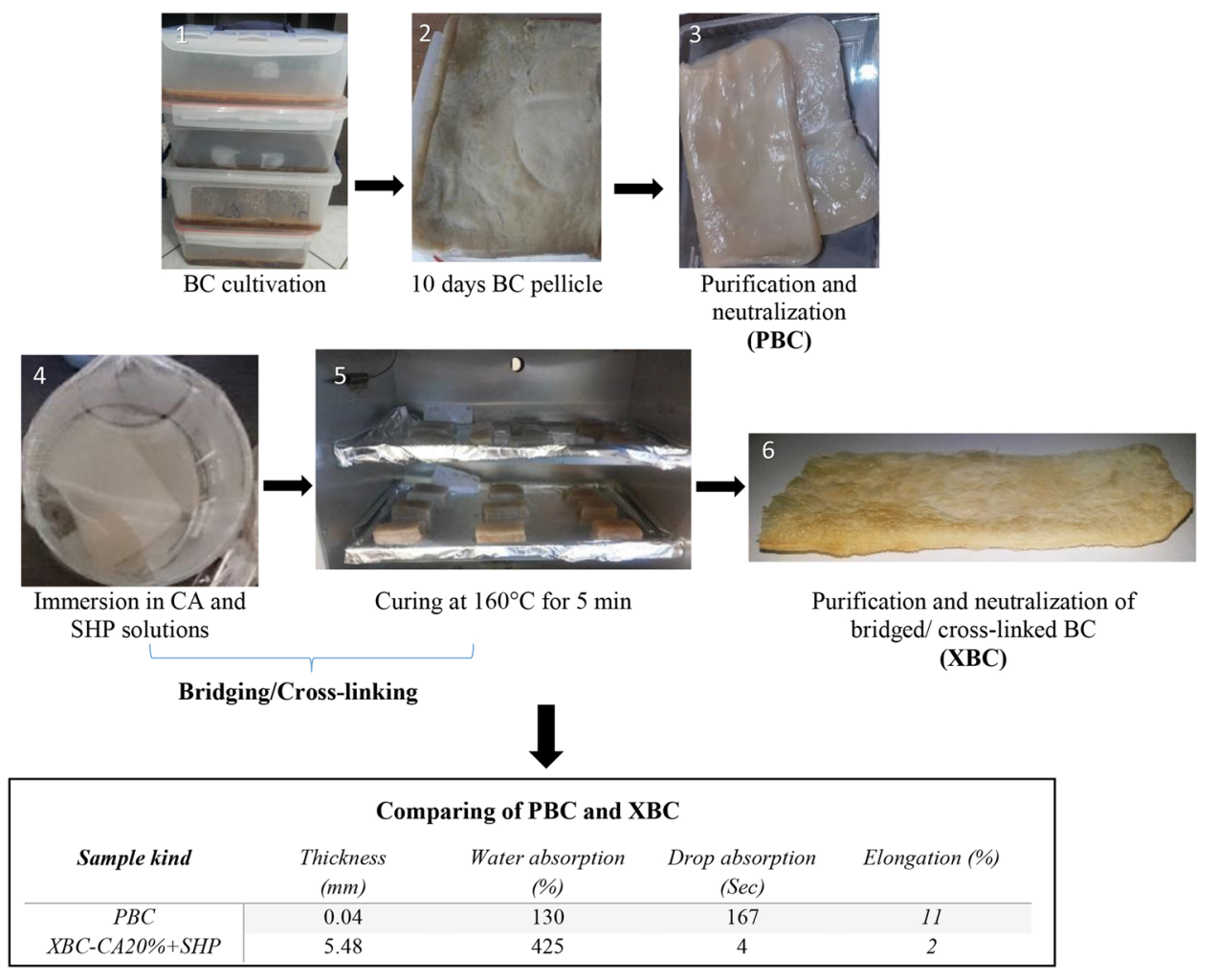

Keywords Bacterial cellulose (BC) $\cdot$ Rehydration · Cross-linking/bridging agent · Citric acid · 3D nanostructure of BC

$\begin{array}{ll}\text { Abbreviations } \\ \text { BC } & \text { Bacterial cellulose } \\ \text { CA } & \text { Citric acid } \\ \text { HS } & \text { Hestrin-Schramm } \\ \text { PBC } & \text { Purified bacterial cellulose } \\ \text { XBC } & \text { Cross-linked/bridged bacterial cellulose } \\ \text { SHP } & \text { Sodium hypophosphate } \\ \text { WSR } & \text { Water swelling rate } \\ \text { BS } & \text { British Standard }\end{array}$

\section{Introduction}

Bacterial cellulose (BC) pellicle is a nanofibrous hydrogel. The most outstanding properties of $\mathrm{BC}$ is compatibility, high water holding capacity, purity, moldability, and biodegradability which has been used for many purposes especially for medical and biomedical fields [1-7]. Accordingly, it has been used in modern wound dressing, artificial blood vessels, drug delivery system, artificial skin, and tissue engineering scaffold [8-12].
Discovering of $\mathrm{BC}$ goes back to the 1880s by Brown, who found it as exopolysaccharides (extra cellular polysaccharide) in vinegar $[13,14]$. This biopolymer is being produced by some bacteria, including $\alpha$-proteobacteria, $\beta$-proteobacteria, $\gamma$-proteobacteria (Gram-negative) and Gram-positive bacteria. It is capable of producing a biofabric in static culture medium which called "pellicle". Due to its 3D structure and internal porosity, $\mathrm{BC}$ is capable of reserving high amount of water ( 99\% dried weight) $[15,16]$.

Although the chemical structure of $\mathrm{BC}$ is similar to the plant cellulose and it is made of linear $\beta$-1,4-glucan chains, it has different physical structure [7]. During cellulose biosynthesis, single nanofibrils are being extruded by bacteria and their assembling in static medium would produce an extracellular gelatinous mat. It consists cellulose I structure and high-crystalline (70-90\%) nanofibres that are distributed in random direction [17]. In addition, hydrogen bonding (H-bonding) is the main reason of BC properties such as plant cellulose. Compared to native cellulose, $\mathrm{BC}$ showed stronger hydrogen bonding with regards to finer and more fibrils. Therefore, most changes of BC in chemical modification are related to H-bonding [16]. 
Purified BC hydrogel comprises nanofibers and a huge amount of water; this provides suitable properties for biomedical usage. Due to the collapse of BC's three-dimensional network after dehydration, re-swelling and water absorption decrease drastically. Although dehydration increases the storage and shelf life of BC, poor rehydration causes limitations when it comes to some biomedical applications $[18,19]$.

Consequently, some studies have been conducted to modify the rehydration of dried BC. Modifications can follow several methods such as in situ modification with the addition of water-soluble materials to the culture medium during the $\mathrm{BC}$ synthesis process, ex situ modification consisting of chemical reactions such as cross-linking and producing interpenetrating polymer networks with other polymers, i.e. fibrin and gelatin, while other researchers have attempted to decrease BC crystallinity or to keep the BC three-dimensional network with freeze drying $[6,19-33]$.

Similarities between the chemical structure of $\mathrm{BC}$ and plant cellulose provide a good opportunity to use plant cellulose cross-linkers in the textile industry to prevent the collapse of BC [25-27]. To the best of the authors' knowledge, previous studies have not reported the use of environmentally friendly plant cellulose cross-linkers alone such as polycarboxylic acids to enhance the rehydration property of BC.

Moreover, citric acid was used in many biomedical studies for instance for cross-linking hydrogels, plant cellulosic materials and bio-composites which count as a safe and nontoxic cross-linker [34-38]. Therefore, in this research, we propose citric acid as a carbohydrate cross-linker on $\mathrm{BC}$ to cross-link nanofibers and maintain the 3D structure of $\mathrm{BC}$ pellicles.

\section{Experiments}

\section{Sample preparation}

10-day BC pellicles (with about $1 \mathrm{~cm}$ thickness) was synthesized by Komagataeibacter xylinus BPR2001 (provided by Collection of Scientific and Industrial Research Center, Tehran, Iran) in Hestrin-Schramm (HS) culture medium (including $20 \mathrm{~g}$ glucose, $5 \mathrm{~g}$ yeast extract, $5 \mathrm{~g}$ peptone, $3.3 \mathrm{~g}$ sodium hydrogen phosphate, $1.15 \mathrm{~g}$ citric acid and $0.5 \mathrm{~g}$ magnesium sulfate) per $1 \mathrm{~L}$ distillated water [39]. Just synthesized samples in the form of pellicles were purified in an alkaline condition (by sodium hydroxide $0.1 \mathrm{~N}$ for $90 \mathrm{~min}$ ). The neutralized pellicles were immersed in different concentrations of citric acid $(5,10$ and $20 \mathrm{w} / \mathrm{v} \%)$ for $24 \mathrm{~h}$ at $30{ }^{\circ} \mathrm{C}$, and $\operatorname{SHP}(2.5,5$ and $10 \mathrm{w} / \mathrm{v} \% ; 1: 2 \mathrm{SHP}$ to $\mathrm{CA})$ was added to the solutions as a catalyst [28]. Then the specimens were cured at $160{ }^{\circ} \mathrm{C}$ for $5 \mathrm{~min}$ and they were washed and rinsed with distilled water until the $\mathrm{pH}$ of samples became $5-6$. Then they were dried at room temperature. Culture medium components were purchased from Merck Co. and other chemicals were provided by Sigma-Aldrich Co.

\section{Characterization techniques}

Differences between the $\mathrm{PBC}$ and $\mathrm{XBC}$ specimens were studied with by ATR-FTIR spectroscopy (Perkin Elmer model Frontier; USA). It was carried out at room temperature in the spectral range from 4000 to $400 \mathrm{~cm}^{-1}$ (its resolution was set to 40 scans).

XRD (model: 3003PTS, SEIFER, Germany) was used to study samples' crystallinity index (CI). CI was calculated by Debye-Scherrer's equation (Eq. 1) from diffracted intensity data using the peak area of the crystalline $\left(I_{002}\right)$ and amorphous regions $\left(I_{\mathrm{am}}\right)$ of the wide-angle X-ray diffraction curves $\left(2 \theta=18^{\circ}\right)[40]$.

$\mathrm{CI}=\left(I_{020}-I_{\mathrm{am}}\right) / I_{020}$.

The morphology and surface characteristics of the treated and untreated (dried at ambient temperature and freeze dried) samples were observed using the SEM microscope (XL30, Philips, The Netherlands). Briefly, the dried samples were fixed on aluminum studs and coated with a gold-palladium under high vacuum conditions before analysis. In addition, some specimens were fractured in liquid nitrogen and sputtered with gold to probe their internal structure and cross-section.

BET analysis was employed at $77 \mathrm{~K}$ to assess the porosity and surface area of the specimens. Thickness was calculated by a micrometer (ACCUD Co.; measuring range: 0-25 mm). Static immersion test method based on the British Standard (BS) 3449:1990 and a drop test method according to BS 4554:1970 were applied to measure wettability. The amount of water absorption capacity in the static immersion test was calculated as

Water absorption $($ Or WSR $)=\left(\left(W_{2}-W_{1}\right) / W_{1}\right) \times 100$

where $W_{1}$ is the dried weight and $W_{2}$ is the wet weight of the samples [20].

For drop test, the specimens were placed over the top of a beaker and a drop of water was dropped on the surface of specimen (from $1 \mathrm{~cm}$ above the surface of sample) and the absorbance time (thorough absorption) of the water drop was recorded [41].

To measure the water swelling rate, specimens were cut into the appropriate size $\left(1 \mathrm{~cm}^{2}\right)$, and after drying they were weighed and immersed in distilled water. Samples were taken out every minute, and after removing extra water with filter papers, they were reweighed. The test was continued 
until the sample weight became constant, and then WSR was determined by the same Eq. (2) [31].

\section{Mechanical properties}

Some of the tensile properties of specimens were measured using a Gotech Tensile Testing Machine (model AL3000, Taiwan) based on ASTM D 882 (the standard test method for tensile elastic properties of thin plastic sheeting). Briefly, rectangular strip $(100 \mathrm{~mm} \times 10 \mathrm{~mm})$ of samples were placed between two metal clamps (about $50 \mathrm{~mm}$ of BC strip was left between two clamps) and then mounted (the extension speed was $2 \mathrm{~mm} / \mathrm{min}$ ) to measure elongation and tenacity. The test was repeated three times in ambient condition and the average values were calculated [19].

\section{Results and discussion}

In this research, it was intended to use the cross-linking ability of citric acid for cross-linking un-dried BC for conserving its structure. The suggested mechanism for the cross-linking process is illustrated in Fig. 1. Citric acid first forms a five-member cyclic anhydride intermediate at an elevated temperature by integrating two adjacent carboxyl groups. The anhydride intermediate then reacts with the hydroxyl group of cellulose chains to form an ester bond [28, 42-44]. Figure 2 shows the differences between the purified and cross-linked BC in color and thickness.

ATR-FTIR spectrums (Fig. 3) display ester bond formation in the treated samples with different concentrations of CA. The specific peaks of BC were observed at $3300-3400 \mathrm{~cm}^{-1}$ (OH group), 1420-1450 $\mathrm{cm}^{-1}$ $\left(\mathrm{CH}_{2}\right.$ scissoring), 1100-1200 $\mathrm{cm}^{-1}(\mathrm{C}-\mathrm{O}-\mathrm{C})$, and $1060 \mathrm{~cm}^{-1}$ (cyclohexane ring) [26, 31, 43]. The peaks at $1710-1740 \mathrm{~cm}^{-1}$ in cross-linked samples (with and without SHP) were related to the ester bond ( $-\mathrm{COO}$ ) made by the cross-linking of the cellulose chains with citric acid. Owing to the removal of unbound citric acid and catalysts by washing (repeated times and reaching to neutral $\mathrm{pH}$ : 5-6), the presence of the carboxyl peak confirmed chemical linkages between citric acid and cellulose chains [31, $42,43]$. In addition, the cross-linking process did not shift the position of the bands in the ATR-FTIR spectra, and except for the $\mathrm{COO}$ bond, the sample peaks did not show any specific difference.
Fig. 1 Suggested mechanism for the cross-linking process of bacterial cellulose with citric acid with regard to the conventional cross-linking of cellulose using citric acid in the presence of acid catalysts $[42,43]$

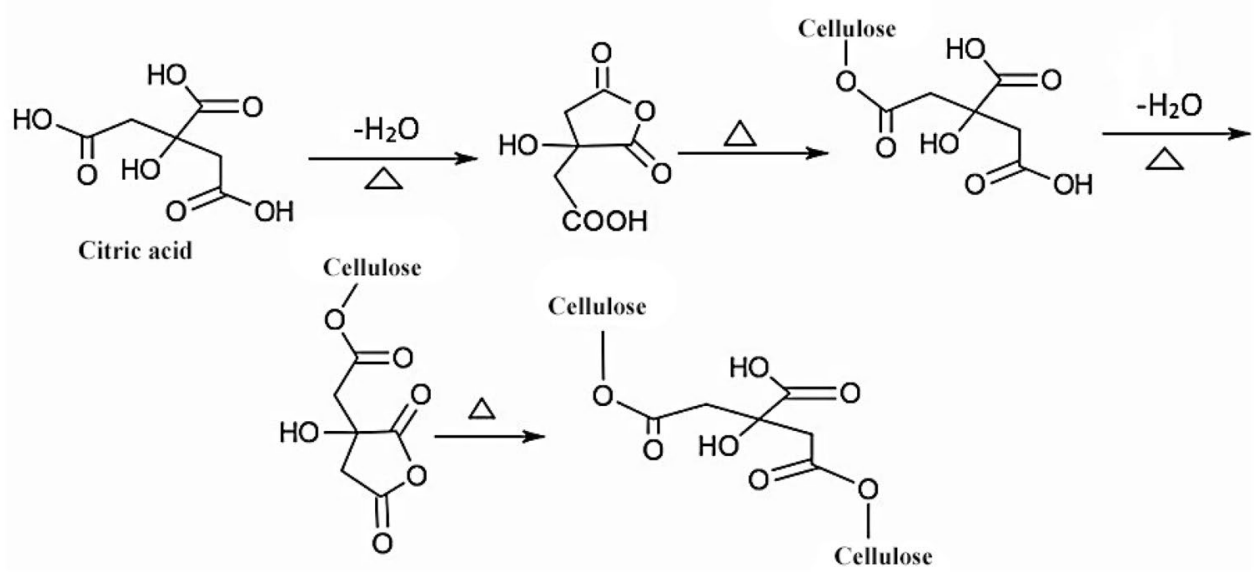

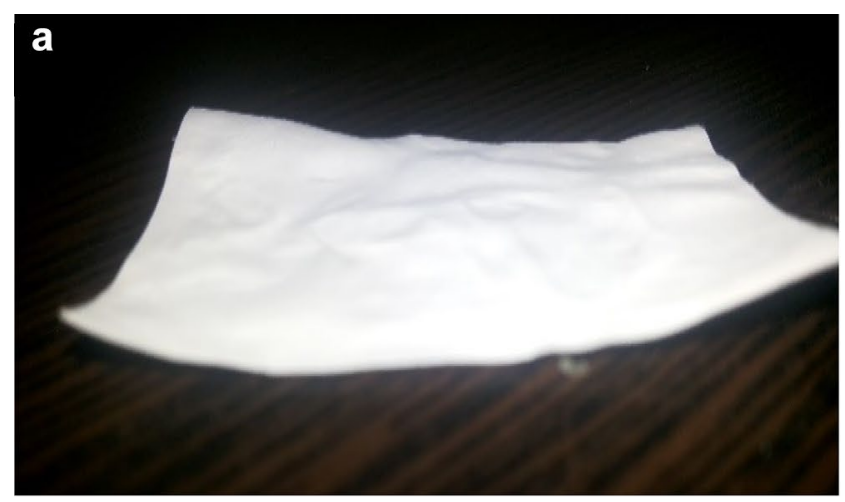

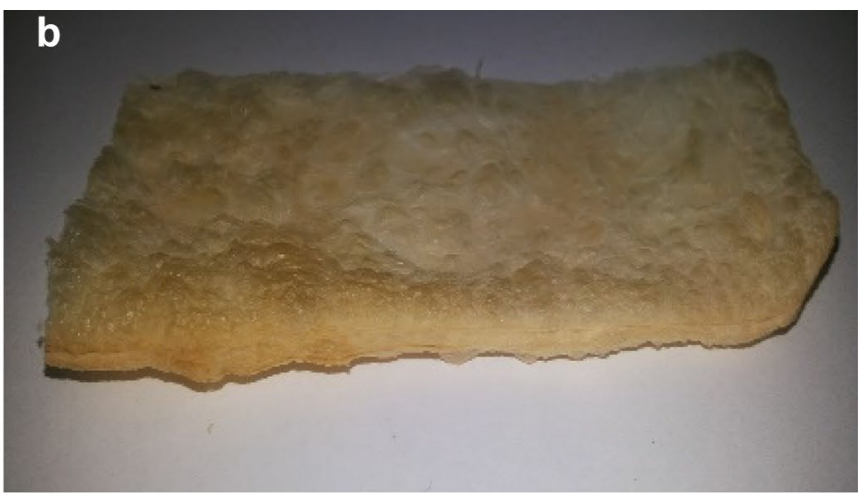

Fig. 2 The images of a PBC and b XBC (CA 20\%+SHP 10\%) in the dry state 


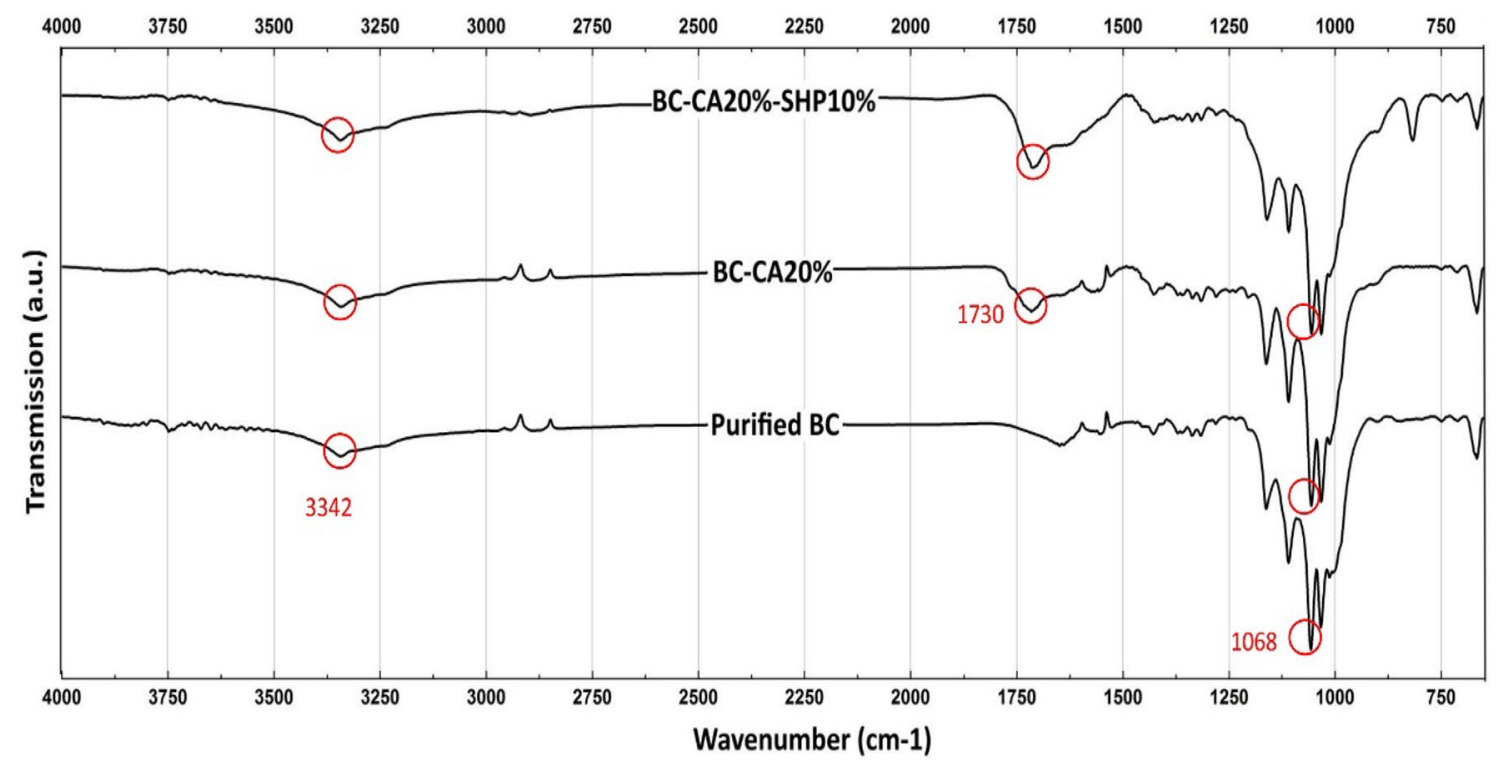

Fig. 3 The spectrum of PBC and XBC with CA 20\% and CA 20\%+SHP 10\%

Table 1 Infrared crystallinity ratio and hydrogen bond intensity of $\mathrm{PBC}$ and $\mathrm{XBC}$ samples

\begin{tabular}{|c|c|c|c|}
\hline \multirow[t]{2}{*}{ Sample kind } & \multicolumn{2}{|c|}{ Infrared crystallinity ratio } & \multirow{2}{*}{$\begin{array}{l}\text { Hydrogen } \\
\text { bond inten- } \\
\text { sity }\end{array}$} \\
\hline & Total crystalline index & Lateral order index & \\
\hline PBC & $0.997 \pm 0.03$ & $0.991 \pm 0.01$ & 1.006 \\
\hline XBC-CA20\% + HSP & $0.997 \pm 0.03$ & $1.005 \pm 0.01$ & 0.993 \\
\hline XBC-CA20\% & $0.985 \pm 0.01$ & $0.998 \pm 0.02$ & 0.995 \\
\hline
\end{tabular}

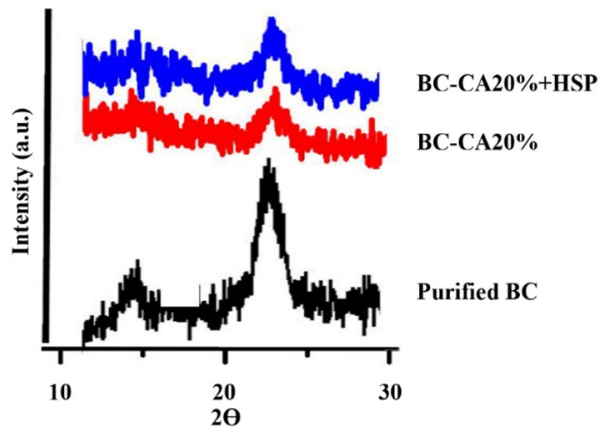

Amount of the crystalline structure of the cellulose indicated a peak around $1427 \mathrm{~cm}^{-1}$ and the band at $900 \mathrm{~cm}^{-1}$ is related to cellulose amorphous region. Using these peaks, lateral order index was calculated which defined empirical crystallinity index (suggested by Nelson and O'Connor). Meanwhile, total crystalline index was obtained from ratio of the peaks at 1372 and $2900 \mathrm{~cm}^{-1}$ and indicated infrared crystallinity (IR) ratio. The hydrogen bond intensity of cellulose that is related to the crystallinity obtained the ratio bands at 3400 and $1320 \mathrm{~cm}^{-1}$.

The obtained results from Table 1 revealed that crosslinking process made no adverse effect on crystallinity. Furthermore, it seems that due to the cross-linking treatment the amount of free $\mathrm{OH}$ group dwindled in treated samples (Table 1).

XRD patterns of PBC and XBC samples are shown in Fig. 4. These diffractograms indicated two main peaks, $2 \theta=22.7^{\circ}$ and $14.7^{\circ}$ in all samples which represented the (002) and (110) lattice diffraction of polymorph, respectively (Table 2). It is in agreement with order-reported data previously. According to Debye-Scherrer's equation, the crystallinity indexes (CI) of all samples were around $60 \%$.
Fig. 4 XRD patterns of PBC and XBC samples

Table 2 Main peaks and their intensity of PBC and XBC samples

\begin{tabular}{llll}
\hline $2 \theta$ & \multicolumn{3}{l}{ Intensity of peaks at specified $2 \theta$} \\
\cline { 2 - 4 } & PBC & $\begin{array}{l}\text { XBC- } \\
\text { CA20\%+HSP }\end{array}$ & XBC-CA20\% \\
\hline $14.65(101)$ & 87 & 74 & 31 \\
$16.8(10 \bar{I})$ & 34 & 26 & 26 \\
$22.75(002)$ & 70 & 72 & 55 \\
18 amorphous & 26 & 26 & 16 \\
\hline
\end{tabular}


As it was expected, it is also confirming that cross-linking takes place in amorphous region of BC [40, 45].

During the drying process, due to the removal of water molecules, nanofibers became closer and bunched together (due to hydrostatic tension), thus connecting and entangling the nanofibers to each other through an irreversible deformation. Consequently, it would be denser with compacted layers and considerable low rehydration ability. We can call this as "collapse phenomenon". The surface and transversal
SEM images were used for tracing the changes after crosslinking and the surface and cross-section of unpurified, purified, treated, and freeze-dried BC are presented in Fig. 5. Figure $5 \mathrm{a}, \mathrm{b}$ shows contaminants such as bacteria and media components that fill pores in the surface and internal structures of unpurified BC. So before purification the absorption ability is low. Figure $5 \mathrm{c}, \mathrm{d}$ shows the nanofibers and layers of purified $\mathrm{BC}$, respectively (surface and transverse images). After purification, impurities would be cleaned and
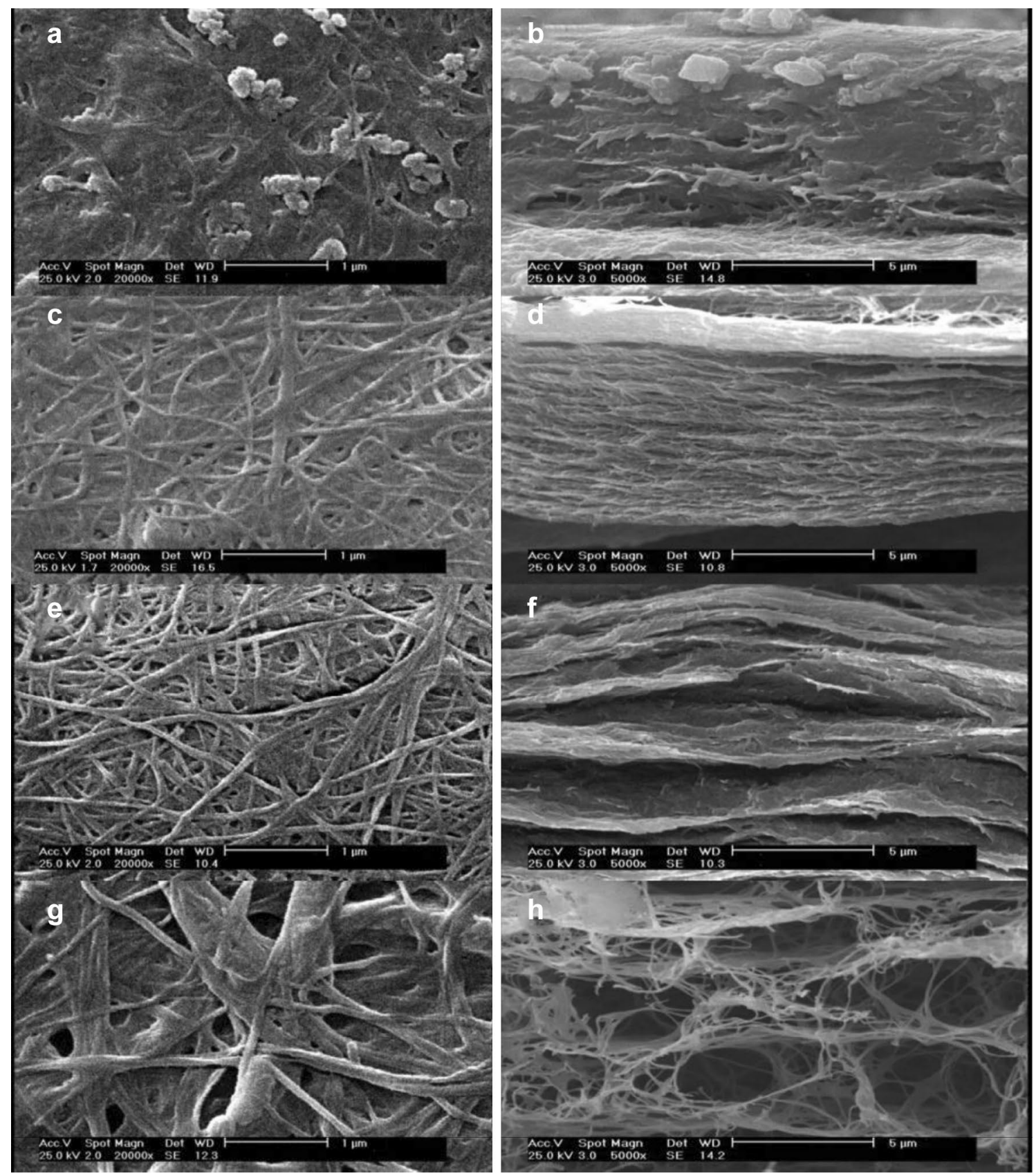

Fig. 5 SEM images of surface and cross-section of unpurified $(\mathbf{a}, \mathbf{b})$, PBC $(\mathbf{c}, \mathbf{d})$, XBC with CA20\% + SHP10\% (e, f), and freeze-dried BC $(\mathbf{g}, \mathbf{h})$, respectively 
the remaining would be just nanofibers and water. The surface and cross-section of the BC treated with $20 \% \mathrm{CA}$ and 10\% SHP are shown in Fig. 5e, f, respectively. The figures show more porosity in the surface and internal structures of the BC 3D network. In addition, the collapse phenomenon was clarified by comparing the surface and cross-section of the freeze-dried BC (Fig. $5 \mathrm{~g}, \mathrm{~h}$ ) with the purified one (Fig. 5c, d). Cross-linking preserves some parts of porosity, and as Fig. 5e, f displays, this process which makes a new construction for BC. The cross-section (transverse image) of the BC treated with $20 \%$ citric acid and $10 \%$ SHP (Fig. 5e and f) proved the existence of higher porosity that increased liquid absorbency. Empty spaces in the modified $\mathrm{BC}$ provide an appropriate place for drug impregnation and also increase rehydration, which is important in biomedical usage. In fact, citric acid with SHP at high temperature could link BC fibrils to each other and support BC's 3D network through $\mathrm{COO}$ bridges in fibers.

Besides SEM observation, BET analysis was also used to investigate the surface area and pore size of the samples (Table 3). The average pore diameter of purified $\mathrm{BC}$ and BC treated with CA 20\% and SHP 10\% were about 28 and $32 \mathrm{~nm}$, with total surface areas of 0.36 and $31.50 \mathrm{~m}^{2} / \mathrm{g}$, respectively.

This reveals that the pore size and surface area of treated $\mathrm{BC}$ are more than those of the untreated samples. Also as it was mentioned previously, pores in the wet $\mathrm{BC}$ structure are filled with water and forms a hydrogel of BC $[18,19]$. During drying, water molecules came out and fibrils gathered together, providing a thin film, and damaged the pores [6]. Cross-linking increased the pore diameter and the surface area by preserving the internal structure of the fibers and their joint points (Table 3 ).

In addition, mechanical properties such as elongation and maximum tensile load before fracture were changed after cross-linking (Table 4). Compared to treated and untreated $\mathrm{BC}$, tensile strength and elongation decreased $\sim 4$ and $\sim 5$ times after cross-linking, respectively. The results indicated that cross-linking process took place between cellulose fibrils so it would decrease the cellulose polymer chain mobility and hence drop the cellulose chain slippage and movement.

Table 3 Porous characteristics of the PBC and XBC samples

\begin{tabular}{llll}
\hline & $\mathrm{S}_{\mathrm{BET}}\left(\mathrm{m}^{2} \mathrm{~g}^{-1}\right)$ & $\begin{array}{l}\text { Total pore } \\
\text { volume } \\
\left(\mathrm{p} / p_{0}=0.990\right) / \\
\left(\mathrm{cm}^{3} \mathrm{~g}^{-1}\right)\end{array}$ & $\begin{array}{l}\text { Average pore } \\
\text { diameter (nitro- } \\
\text { gen desorption)/ } \\
(\mathrm{nm})\end{array}$ \\
\hline $\mathrm{PBC}$ & 0.36211 & 0.002558 & 28.255 \\
$\mathrm{XBC}-$ & 31.499 & 0.2512 & 31.905 \\
$\mathrm{CA} 20 \%+\mathrm{SHP}$ & & & \\
\hline
\end{tabular}

Table 4 Comparing mechanical properties of $\mathrm{PBC}$ and $\mathrm{XBC}$ with CA $20 \mathrm{w} / \mathrm{v} \%$ and HSP $10 \%$

\begin{tabular}{lcl}
\hline Sample kind & Elongation (\%) & $\begin{array}{l}\text { Maximum tensile } \\
\text { load before fracture } \\
(\mathrm{N})\end{array}$ \\
\hline PBC & 11 & 30 \\
XBC-CA20\%+HSP & 2 & 8 \\
\hline
\end{tabular}

The result obtained by assessing the layer's thickness in Fig. 6 showed that, by increasing the concentration of acid and catalysts, the thickness of the cross-linked specimens increased. Consequently, the thickness of the sample with $20 \%$ acid and 10\% SHP was 137 times more than that of the purified sample. Meanwhile, the effect of SHP on the crosslinking process was obvious. The SHP catalyst facilitated the reaction between cellulose chains and citric acid to enhance cross-linking [46].

The water re-absorption ability and drop absorption time are counting as two significant factors for wet ability, so they were determined for treated and pristine samples and the obtained results are revealed in Fig. 6. The results indicated that the water absorption ability of samples would be improved by increasing citric acid concentration, which are also in agreement with thickness and BET results. The sample with $20 \%$ citric acid and 10\% SHP absorbed water $~ 3$ times more than the raw one. In the water absorption test, the main reason for ascending the weight of the cross-linked samples was the amount of water entrapped inside the structure, because before weighing the extra water on the surface of the samples, water was removed by shaking. According to the SEM, BET, and thickness results, the increase in porosity can lead to more rehydration. Therefore, rehydration was enhanced by increasing the cross-linking of the sample, which plays an important role in water holding when it comes to biomedical applications such as wound dressing $[18,32]$. Owing to greater porosity on the surface of the treated samples, which was confirmed by SEM (Fig. 5), the results showed faster absorption for the cross-linked BC. It is also worth mentioning that the cross-linking treatment prevents interring fibers into each other and collapsing of the 3D network. In this regard, cross-linked specimens can absorb water faster than purified samples, and the spongy form of these samples causes a huge difference in their surface morphology compared with the untreated one.

The WSR results are displayed in Fig. 7. According to other test results, the sample that was treated with $20 \%$ citric acid and SHP showed higher SWR. Based on the test method, the weight of the purified sample became constant after $3 \mathrm{~min}$, and the sample with 20\% citric acid and 10\% SHP was saturated after $7 \mathrm{~min}$. This confirmed a long distance between the layers of the normal and the cross-linked specimens. This property has a significant role in some 
Fig. 6 Comparison of the thickness, drop absorption time, and water absorption of $\mathrm{PBC}$ and $\mathrm{XBC}$ with 5,10 , and $20 \%$ citric acid (graph and data table)

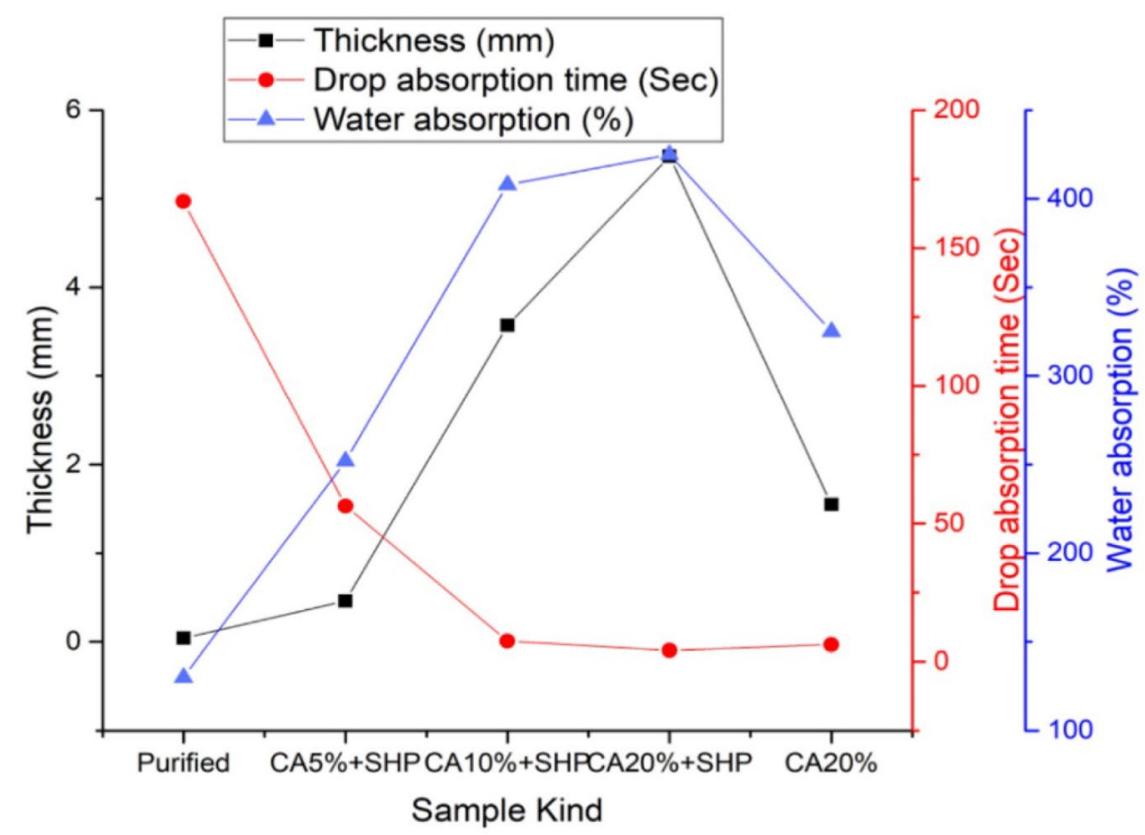

\begin{tabular}{|c|c|c|c|}
\hline Sample & $\begin{array}{c}\text { Thickness } \\
\text { (mm) }\end{array}$ & $\begin{array}{c}\text { Water absorption } \\
(\%)\end{array}$ & $\begin{array}{c}\text { Drop absorption } \\
\text { (Sec) }\end{array}$ \\
\hline$P B C$ & 0.04 & 130 & 167 \\
\hline$X B C-C A 5 \%+S H P$ & 0.46 & 252 & 56 \\
\hline$X B C-C A 10 \%+S H P$ & 3.57 & 408 & 7 \\
\hline$X B C-C A 20 \%+S H P$ & 5.48 & 425 & 4 \\
\hline$X B C-C A 20 \%$ & 1.55 & 325 & 6 \\
\hline
\end{tabular}

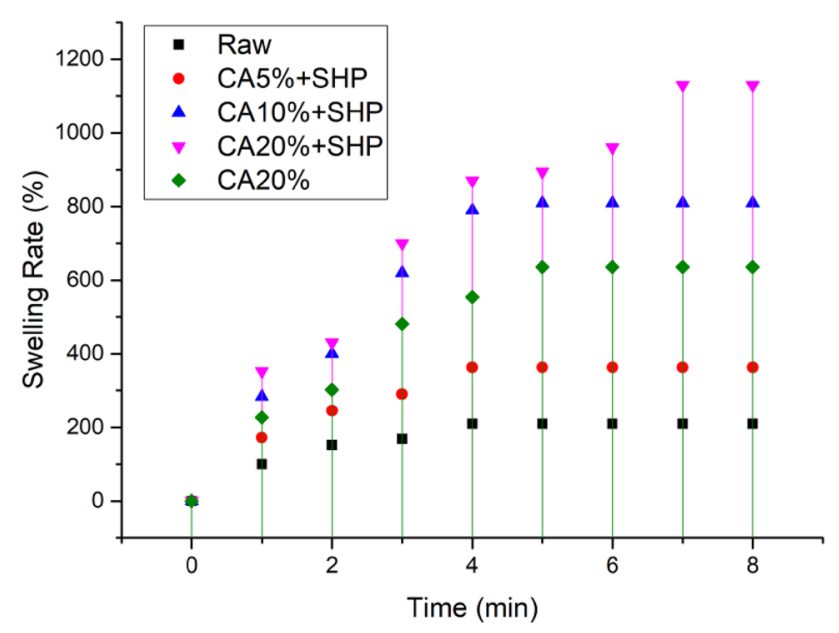

Fig. 7 Comparing water swelling rate of $\mathrm{PBC}$ and $\mathrm{XBC}$ with 5, 10, and $20 \mathrm{w} / \mathrm{v} \%$ citric acid

biomedical procedures such as wound dressing. Based on the physical and chemical structures of $\mathrm{BC}$, it seems that water molecules can absorb in modified BC physically (porosity) and chemically (hydrogen bonding with $\mathrm{OH}$ groups), and thus, cross-linked $\mathrm{BC}$ can overcome the rehydration weakness. Meanwhile, BC treated with free formaldehyde materials such as polycarboxylic acids has high potential for use in biomedical applications such as environmentally friendly and biocompatible products.

\section{Conclusion}

Bacterial cellulose is a versatile green polymer and it has a wide variety of applications. It indicates many potential properties and also it could be obtained from wasted materials with carbohydrate sources. But after drying process, BC pellicle would initially be collapsed into a dense layer with less rehydration. For the first time in this study, citric acid was proposed as a cross-linking agent to prevent BC from condensing during rehydration. This formed carboxylic bridges between cellulose fibril chains, thereby preventing its condensation during drying. The resultant of $\mathrm{BC}$ showed a significant rehydration ability that was five times higher than the ordinary one. Moreover, it revealed 
a higher porosity, wettability, and water swelling rate compared to the untreated sample. According to the results of this research, cross-linked BC with citric acid has high potential for using in the biomedical sector.

Open Access This article is distributed under the terms of the Creative Commons Attribution 4.0 International License (http://creativeco mmons.org/licenses/by/4.0/), which permits unrestricted use, distribution, and reproduction in any medium, provided you give appropriate credit to the original author(s) and the source, provide a link to the Creative Commons license, and indicate if changes were made.

\section{References}

1. Fu, L., Zhang, J., Yang, G.: Present status and applications of bacterial cellulose-based materials for skin tissue repair. Carbohydr. Polym. 92, 1432-1442 (2013)

2. Hu, W., Chen, S., Yang, J., Li, Z., Wang, H.: Functionalized bacterial cellulose derivatives and nanocomposites. Carbohydr. Polym. 101, 1043-1060 (2014)

3. Huang, Y., Zhu, C., Yang, J., Nie, Y., Chen, C., Sun, D.: Recent advances in bacterial cellulose. Cellulose 21(1), 1-30 (2014)

4. Qiu, Y., Qiu, L., Cui, J., Wei, Q.: Bacterial cellulose and bacterial cellulose-vaccarin membranes for wound healing. Mater. Sci. Eng. C 59, 303-309 (2016)

5. Rajwade, J.M., Paknikar, K.M., Kumbhar, J.V.: Applications of bacterial cellulose and its composites in biomedicine. Appl. Microbiol. Biotechnol. 99, 2491-2511 (2015)

6. Stumpf, T.R., Pértile, R.A., Rambo, C.R., Porto, L.M.: Enriched glucose and dextrin mannitol-based media modulates fibroblast behavior on bacterial cellulose membranes. Mater. Sci. Eng. C 33, 4739-4745 (2013)

7. Sulaeva, I., Henniges, U., Rosenau, T., Potthast, A.: Bacterial cellulose as a material for wound treatment: properties and modifications. A review. Biotechnol. Adv. 33, 1547-1571 (2015)

8. Picheth, G.F., Pirich, C.L., Sierakowski, M.R., Woehl, M.A., Sakakibara, C.N., de Souza, C.F., Martin, A.A., da Silva, R., de Freitas, R.A.: Bacterial cellulose in biomedical applications: a review. Int. J. Biol. Macromol. 104, 97-106 (2017)

9. Gao, X., Shi, Z., Kusmierczyk, P., Liu, C., Yang, G., Sevostianov, I., Silberschmidt, V.V.: Time-dependent rheological behaviour of bacterial cellulose hydrogel. Mater. Sci. Eng. C 58, 153-159 (2016)

10. Gao, X., Kusmierczyk, P., Shi, Z., Liu, C., Yang, G., Sevostianov, I., Silberschmidt, V.V.: Through-thickness stress relaxation in bacterial cellulose hydrogel. J. Mech. Behav. Biomed. Mater. 59, 90-98 (2016)

11. Pandey, M., Mohamad, N., Low, W.L., Martin, C., Amin, M.C.I.M.: Microwaved bacterial cellulose-based hydrogel microparticles for the healing of partial thickness burn wounds. Drug. Deliv. Transl. Res. 7, 89-99 (2017)

12. Yuan, N., Xu, L., Zhang, L., Ye, H., Zhao, J., Liu, Z., Rong, J.: Superior hybrid hydrogels of polyacrylamide enhanced by bacterial cellulose nanofiber clusters. Mater. Sci. Eng. C 67, 221-230 (2016)

13. Römling, U., Galperin, M.Y.: Bacterial cellulose biosynthesis: diversity of operons, subunits, products, and functions. Trends Microbiol. 23(9), 545-557 (2015)

14. Lin, S.P., Calvar, I.L., Catchmark, J.M., Liu, J.R., Demirci, A., Cheng, K.C.: Biosynthesis, production and applications of bacterial cellulose. Cellulose 20(5), 2191-2219 (2013)
15. Ashjaran, A., Yazdanshenas, M.E., Rashidi, A., Khajavi, R., Rezaee, A.: Overview of bio nanofabric from bacterial cellulose. J. Text. Inst. 104(2), 121-131 (2013)

16. Abeer, M.M., Mohd Amin, M.C.I., Martin, C.: A review of bacterial cellulose-based drug delivery systems: their biochemistry, current approaches and future prospects. J. Pharm. Pharmacol. 66(8), 1047-1061 (2014)

17. Reiniati, I., Hrymak, A.N., Margaritis, A.: Recent developments in the production and applications of bacterial cellulose fibers and nanocrystals. Crit. Rev. Biotechnol. 37(4), 510-524 (2017)

18. Ul-Islam, M., Khan, T., Park, J.K.: Water holding and release properties of bacterial cellulose obtained by in situ and ex situ modification. Carbohydr. Polym. 88, 596-603 (2012)

19. Ul-Islam, M., Khattak, W.A., Kang, M., Kim, S.M., Khan, T., Park, J.K.: Effect of post-synthetic processing conditions on structural variations and applications of bacterial cellulose. Cellulose 20, 253-263 (2013)

20. Meftahi, A., Khajavi, R., Rashidi, A., Sattari, M., Yazdanshenas, M.E., Torabi, M.: The effects of cotton gauze coating with microbial cellulose. Cellulose 17, 199-204 (2010)

21. Brown, E.E., Laborie, M.P.G., Zhang, J.: Glutaraldehyde treatment of bacterial cellulose/fibrin composites impact on morphology, tensile and viscoelastic properties. Cellulose 19, 127-137 (2012)

22. Brown, E.E., Zhang, J., Laborie, M.P.G.: Never-dried bacterial cellulose/fibrin composites: preparation, morphology and mechanical properties. Cellulose 18, 631-641 (2011)

23. Cacicedo, M.L., Castro, M.C., Servetas, I., Bosnea, L., Boura, K., Tsafrakidou, P., Dima, A., Terpou, A., Koutinas, A., Castro, G.R.: Progress in bacterial cellulose matrices for biotechnological applications. Bioresour. Technol. 213, 172-180 (2016)

24. Tang, W., Jia, S., Jia, Y., Yang, H.: The influence of fermentation conditions and post-treatment methods on porosity of bacterial cellulose membrane. World J. Microbiol. Biotechnol. 26, 125 (2010)

25. Gao, C., Wan, Y., Yang, C., Dai, K., Tang, T., Luo, H., Wang, $\mathrm{J}$.: Preparation and characterization of bacterial cellulose sponge with hierarchical pore structure as tissue engineering scaffold. J. Porous Mater. 18, 139-145 (2011)

26. Wang, J., Wan, Y.Z., Luo, H.L., Gao, C., Huang, Y.: Immobilization of gelatin on bacterial cellulose nanofibers surface via crosslinking technique. Mater. Sci. Eng. C 32, 536-541 (2012)

27. Castro, C., Cordeiro, N., Faria, M., Zuluaga, R., Putaux, J.L., Filpponen, I., Ganán, P.: In-situ glyoxalization during biosynthesis of bacterial cellulose. Carbohydr. Polym. 126, 32-39 (2015)

28. Reddy, N., Yang, Y.: Citric acid cross-linking of starch films. Food Chem. 118, 702-711 (2010)

29. Chang, S.T., Chen, L.C., Lin, S.B., Chen, H.H.: Nano-biomaterials application: morphology and physical properties of bacterial cellulose/gelatin composites via crosslinking. Food Hydrocoll. 27, 137-144 (2012)

30. Dahman, Y.: Nanostructured biomaterials and biocomposites from bacterial cellulose nanofibers. J. Nanosci. Nanotechnol. 9, 5105-5122 (2009)

31. Fijałkowski, K., Żywicka, A., Drozd, R., Niemczyk, A., Junka, A.F., Peitler, D., Kordas, M., Konopacki, M., Szymczyk, P., El Fray, M., Rakoczy, R.: Modification of bacterial cellulose through exposure to the rotating magnetic field. Carbohydr. Polym. 133, 52-60 (2015)

32. Shah, N., Ul-Islam, M., Khattak, W.A., Park, J.K.: Overview of bacterial cellulose composites: a multipurpose advanced material. Carbohydr. Polym. 98, 1585-1598 (2013)

33. Seifert, M., Hesse, S., Kabrelian, V., Klemm, D.: Controlling the water content of never dried and reswollen bacterial cellulose by the addition of water-soluble polymers to the culture medium. J. Polym. Sci. A Polym. Chem. 42, 463-470 (2004) 
34. Xu, F., Weng, B., Gilkerson, R., Materon, L.A., Lozano, K.: Development of tannic acid/chitosan/pullulan composite nanofibers from aqueous solution for potential applications as wound dressing. Carbohydr. Polym. 115, 16-24 (2015)

35. Pinho, E., Soares, G.: Functionalization of cotton cellulose for improved wound healing. J. Mater. Chem. B 6(13), 1887-1898 (2018)

36. Gyawali, D., Tran, R.T., Guleserian, K.J., Tang, L., Yang, J.: Citric-acid-derived photo-cross-linked biodegradable elastomers. J. Biomater. Sci-Polym. Ed. 21(13), 1761-1782 (2010)

37. Capanema, N.S., Mansur, A.A., de Jesus, A.C., Carvalho, S.M., de Oliveira, L.C., Mansur, H.S.: Superabsorbent crosslinked carboxymethyl cellulose-PEG hydrogels for potential wound dressing applications. Int. J. Biol. Macromol. 106, 1218-1234 (2018)

38. El Fawal, G.F., Abu-Serie, M.M., Hassan, M.A., Elnouby, M.S.: Hydroxyethyl cellulose hydrogel for wound dressing: fabrication, characterization and in vitro evaluation. Int. J. Biol. Macromol. 111, 649-659 (2018)

39. Ebrahimi, E., Babaeipour, V., Meftahi, A., Alibakhshi, S.: Effects of bio-production process parameters on bacterial cellulose mechanical properties. J. Chem. Eng. Jpn 50(11), 857-861 (2017)

40. Khajavi, R., Esfahani, E.J., Sattari, M.: Crystalline structure of microbial cellulose compared with native and regenerated cellulose. Int. J. Polym. Mater. 60(14), 1178-1192 (2011)
41. Prabhu, S., Vaideki, K., Anitha, S.: Effect of microwave argon plasma on the glycosidic and hydrogen bonding system of cotton cellulose. Carbohydr. Polym. 156, 34-44 (2017)

42. Awada, H., Montplaisir, D., Daneault, C.: Cross-linking of papers based on thermomechanical pulp fibers by polycarboxylic acids: influence on the wet breaking length. Ind. Eng. Chem. Res. 53(11), 4312-4317 (2014)

43. Widsten, P., Dooley, N., Parr, R., Capricho, J., Suckling, I.: Citric acid crosslinking of paper products for improved high-humidity performance. Carbohydr. Polym. 101, 998-1004 (2014)

44. Grande, C.J., Torres, F.G., Gomez, C.M., Troncoso, O.P., CanetFerrer, J., Martínez-Pastor, J.: Development of self-assembled bacterial cellulose-starch nanocomposites. Mater. Sci. Eng. C 29, 1098-1104 (2009)

45. Poletto, M., Ornaghi, H.L., Zattera, A.J.: Native cellulose: structure, characterization and thermal properties. Materials 7(9), 6105-6119 (2014)

46. Ye, T., Wang, B., Liu, J., Chen, J., Yang, Y.: Quantitative analysis of citric acid/sodium hypophosphite modified cotton by HPLC and conductometric titration. Carbohydr. Polym. 121, 92-98 (2015)

Publisher's Note Springer Nature remains neutral with regard to jurisdictional claims in published maps and institutional affiliations.

\section{Affiliations}

\section{A. Meftahi ${ }^{1}$ - R. Khajavi ${ }^{2}$ - A. Rashidi ${ }^{1}$ - M. K. Rahimi ${ }^{3} \cdot$ A. Bahador ${ }^{4}$}

R. Khajavi

rkhajavi@gmail.com

1 Department of Textile, Science and Research Branch, Islamic Azad University, Tehran, Iran

2 Department of Polymer and Textile Engineering, South Tehran Branch, Islamic Azad University, Tehran, Iran
Department of Microbiology, Tehran Medical Branch, Islamic Azad University, Tehran, Iran

4 Department of Microbiology, Faculty of Medicine, Tehran University of Medical Sciences, Tehran, Iran 